\title{
History of Romanian Medical Informatics: Learning from the Past to Reshape the Future
}

\author{
George I. Mihalas' ${ }^{1}$ Lacramioara Stoicu-Tivadar ${ }^{2}$ \\ 1 Academy of Medical Sciences, Timisoara Branch, Romania \\ 2 University Politehnica Timisoara, Romania
}

\begin{abstract}
Summary
Objectives: The paper presents a review of the history of medical informatics in Romania, starting from the pioneering works, relating the present, and foreseeing the future.

Methods: Major milestones of the development of this field have not been simply enumerated, but described within the specific socio-political frame, grasping the entire context over the last four decades in Romania. Two main perspectives have been traced: education and training in medical informatics and implementations in healthcare.

Results: Four distinctive historical periods are identified and the major events of each period are described in a critical manner. The history of the Romanian Society of Medical Informatics is presented in a separate chapter. The last section is dedicated to the present state of the field in Romania.

Conclusion: The history of Romanian Medical Informatics spans many years and is rich in content. The Romanian Society of Medical Informatics is mainly the result of the efforts undertaken by an enthusiastic and sound professional community, trying to continue the tradition, to achieve new goals, and to work as an active member of the international biomedical/health informatics community.
\end{abstract}

\section{Keywords}

Medical Informatics/history; technology development; education ; health information systems; Romania

Yearb Med Inform 2018:243-51

http://dx.doi.org/ 10.1055/s-0038-1641203

\section{Introduction}

Medical informatics, as an interdisciplinary domain, has developed in the second half of the last century as a natural application of computer science technology in various fields, including healthcare. However, the relationship with the bio-medical domain had some unique features, transforming medical informatics into one of the most dynamic disciplines, unveiling new aspects, raising new problems, facing new challenges, pushing the development of new technologies, and promising higher care quality and new approaches to healthcare and adjacent fields. Moreover, besides the fast-technological advent, the major socio-political changes of the last two decades of the $20^{\text {th }}$ century, especially in Europe, left their mark over the development of medical informatics in various countries. Therefore, a historical approach to our domain should not be reduced to a mere list of events, actions, or people, but should rather interpret them, highlight the major achievements, and trace the trends throughout each period [1].

Our paper attempts to offer the reader such a view over the birth and development of medical informatics in Romania within its specific socio-political environment, with its ups and downs, marking the milestones, and analysing the present state. For the historical part, we followed the staging proposed in [2], presenting the difficulties encountered at the beginning, the efforts conducted to promote research and education, the role of industry, the relations with governmental institutions, and international collaborations and activities. The last part presents our recent activities and plans for the near future.

\section{Historical View on Medical Informatics in Romania}

\section{2a Pioneering Period}

The socio-political context during the late 60 's and the beginning of the 70's in Romania was favourable to the promotion of new areas, especially those linked to technological developments. The communist party was committed to demonstrate the capacity to cope with the worldwide technological advent and computer science was among the areas which enjoyed strong official support. The emphasis was on industrial applications; however, a couple of small research groups were created, approaching various topics, including medical applications of computer science research, e.g. Dan Farcas and Vasile Baltac from Timisoara worked on the modelling of inter-neuronal connections [3], and Mihai Angelescu and Nicolae Mihalas in Arad proposed a diagnosis system for gastrointestinal diseases ${ }^{1}$. However, the impact of such research was low and collaborations with scientists from other countries were very difficult; we only had access to some East European scientific journals and the participation in international scientific events was very limited. Actually almost any external individual contact could raise suspicions of a hidden illegal activity. All external contacts had to be initiated, or, at least, approved by the authorities.

Things started to partially change after a seminar on medical applications of informatics organized in 1969 in Bucharest for the leading staff of the MoH by IBM's Vienna branch where speakers from Karolinska

\footnotetext{
The program was presented in a regional conference without printed volume.
} 
University, Sweden, were invited. Soon after, the Centre of Statistics of the $\mathrm{MoH}$ was created; later it became the Computer Centre of the $\mathrm{MoH}$ and a leading institution involved in the implementation of information technology in the Romanian healthcare system [4].

In the early 70 's, the political context resulting from Romania's position against the invasion of Czechoslovakia generated an enthusiastic atmosphere, which, unfortunately, lasted only a couple of years. In that period, most central institutions and territorial authorities were equipped by computer centres. Education and training of professionals in this new area became a real need; informatics became a mandatory discipline in almost all technical schools yielding a new generation of well-prepared computer scientists. The fast development of information technology imposed frequent "update meetings", transformed into annual scientific conferences "Informatics for Management", which started in 1975 in Cluj-Napoca. In 1977, the third edition of the conference introduced a new section dedicated to medical applications, held as a separate National Symposium in Satu-Mare, thus marking the first official event solely dedicated to medical informatics in Romania.

\section{2b Childhood and Youth Period}

The first National Symposium of Medical Informatics in Satu-Mare (1977), coordinated by Dr. Virgil Enatescu, was a milestone in Romanian medical informatics. It gathered around a hundred of participants (physicians, healthcare providers, engineers, and mathematicians). At that time, it became very clear that the use of computers in medical practice and research was a process which had just started, the complexity of applications was expected to be high, and the medicine of the future would rely to a great extent on technological developments, including information technology. This was the start of subsequent annual meetings, initially called "MEDINF", now known as "RO-MEDINF". A community of professionals from various domains, interested in medical informatics, was formed since the first edition of the National Symposium. The community has been growing year after year, becoming the present Romanian Society of Medical Informatics (RSMI).
The Computer Centre of the Ministry of Health was equipped in 1976 with a Felix-256 computer (the Romanian version of IBM-360), used mainly for health statistics and hosting various databases. In 1978, the newly created Central Institute of Informatics (ICI) - the official coordinator of all national programs dedicated to the introduction of information technology in all domains (industry, transport, local administration... etc.) - initiated an ambitious project - SIROS (Information System for Healthcare), planned to be structured in three levels: central, territorial, and healthcare units. Unfortunately, this project proved to be too expensive and unrealistic; only a couple of components at the central level were completed and, eventually, ICI abandoned the project [4]. However, the idea of creating a national information system for healthcare remained on the list of the future projects of the Romanian leadership.

By the beginning of the 80's, the Institute of Medicine in Timisoara (today "Victor Babes" University of Medicine and Pharmacy) managed to obtain an M-18 microcomputer for research purposes, especially in preclinical disciplines (biophysics, normal and pathological physiology, pharmacology etc.). A library of statistical programs was developed. This had a major impact, especially among the young staff of the university, with several doctorate-level students also expressing their desire to learn how to process their experimental or clinical data by themselves. This context created the conditions to propose a course of medical informatics to medical students. After overcoming some initial bureaucratic obstacles, the course was introduced as an optional course in 1984. The success was obvious, granted by the modern structure of the content, built on a Western model. Indeed, we should mention here the support received from Prof. Jan H. van Bemmel who sent us several articles about the medical informatics courses that were held in the Netherlands [5]. Hence, we had a modern and comprehensive structure of medical informatics courses from the very beginning. Practical works were mostly limited to demos, but even the few hands-on hours were very attractive and had an "addictive" effect.

An important and specific factor for the period was the possibility to keep external contacts thanks to Jana Zvarova's initiative, supported by Jan van Bemmel and other scientists, to organize yearly meetings in Prague (period 1985-1990). The location was excellent: beyond the "iron curtain", inside the communist block, accessible to people from Eastern Europe, but also close and easily accessible from Western European countries [1].

By 1985, the Computer Centre of the Ministry of Health, led by Dr. Ovidiu Popescu, started a series of courses (similar to nowadays Continuous Medical Education - CME programs) for the medical staff from the whole country, following the course structure we offered to medical students in Timisoara, and adding some specific applications for healthcare units and hospital management. These courses were developed by Dr. Dan Farcas and his team. The main merit of these courses was their contribution to raising the awareness about the potential use of information systems in healthcare, as most of the attendants of these courses had leading positions either in hospitals or at the level of local healthcare authorities.

In the late 80's, some hospitals (Clinical Hospital "Fundeni" and Military Hospital in Bucharest, Town Hospital Borsa in Maramures county, District Hospitals in Tirgu-Mures and Craiova...etc.) started to develop components of hospital information systems: patient databases, early forms of electronic health records (EHRs), hospital resource management, personnel databases... etc. But the most significant work was performed in medical research, mainly in university laboratories and clinics. The involvement of healthcare authorities was minimal.

The experience of that period, especially from the courses organized by the Computer Centre of the $\mathrm{MoH}$, was synthesized in a monograph of Medical Informatics, rewarded in 1990 with "Gheorghe Marinescu" Prize of the Romanian Academy [6].

\section{2c Consolidation Period}

The last decade of the twentieth century was the period of a great change throughout Eastern Europe, which had an impact on all aspects of social life, including education and healthcare. Population expectations and initiatives showed a major sudden change, 
while institutions, legislation, resources, and mentalities remained far behind. That is why some actions or events are difficult to be correctly interpreted and/or understood, comprising a mixture of -sometimes contradictory - features.

In the medical informatics domain, the most important event in Romania took place in the spring of 1990 in Sibiu, when the participants in the annual national conference of medical informatics decided to organize and create the Romanian Society of Medical Informatics. This had a strong impact and will be detailed in a separate chapter.

\section{a) Education and Training}

Several major reforms and concerted actions started in parallel in 1990 at a nationwide scale. The educational system underwent major changes: universities gained more independence, curricula and syllabi could be decided by their senates. Hence, it was not surprising that by 1992 all medical schools in Romania included medical informatics as a mandatory discipline for medical students in all specialties - general medicine, dentistry, pharmacy, and nursing [7]. The structure of the courses in Timisoara served as a model for most of them and it was close to the $\mathrm{Eu}$ ropean curricula [8] and IMIA recommendations [9]. In most cases, medical Informatics courses included biostatistics [10].

The PhD program in medical informatics, which started officially in 1992 in Timisoara as well, was created to allow students to approach advanced research topics and to cover the growing need of high-level professionals [11].

The central objective of the period was to develop a coherent strategy for medical informatics education in Romania [12]. The objective was almost entirely achieved due to the annual meetings of the RSMI, which represented a milestone for subsequent actions [13].

A specific feature of this period was the fact that information technology became accessible. There was no specific development dedicated to medical education, the focus in most departments moved towards the development of laboratory practical works $[10,14]$. Specific courses and practical works were developed for various medical specialties (dentistry, pharmacy, kineto-therapy, and nursing) $[11,15]$. By the end of this decade, medical informatics had gained the status of a mandatory and independent discipline in the syllabus of all medical schools in Romania.

A positive effect was brought in by the development of an adjacent field - medical (bio)engineering. New faculties integrated this field in their curriculum in Iassy (F. Topoliceanu, 1994) and Bucharest (A. Morega, S. Kostrachievici, 2010), and there were specific programs in Timisoara (D. Dragulescu and M. Tascau, 1995) and Cluj-Napoca (R. Ciupa, 1995).

\section{b) Implementations in Healthcare}

The political context of the early 90's in Romania favoured an intense external cooperation and healthcare was a sector which was included in several programs with external funding, mostly from the World Bank. While for education and training, developments were relatively smooth and uniform, the implementation of information systems and of various information technology (IT) applications in the healthcare system was quite uneven, often having to overcome unexpected obstacles. One of the first big project frames, called "3409-RO", with a total cost estimate of $\sim 150 \mathrm{M} \$$, started in 1991. It was dedicated to "rehabilitation of healthcare in Romania" and included an IT (Information Technology) component of $\sim 2 \mathrm{M} \$$ [4]. Results were not spectacular, as the budget was split into several small independent projects, being spent mainly on infrastructure components at the central level and for some big hospitals (buying computers), as well as for the implementation of some courses. A good example of a successful project was the system developed by the ambulance service in Bucharest [16]: the information system was integrated within the emergency call centre, with an accurate track of all calls and available personnel, its implementation led to a substantial reduction in call response time and an increased satisfaction of both staff and population. But, in most cases, the applications were limited to the fulfilment of routine tasks. This allowed us to learn how important it was to develop a long-term strategy and to build a large project relying on a thorough analysis of the complexity of the healthcare system, and including (high-) performance software as well as a carefully organized program for training the staff involved in the exploitation of the project.

Thus, the second part of "3409-RO" turned into a new ambitious project entitled "Healthcare Medical Information System" - HMIS [17], with an initial budget of 18 M\$ and a potential extension of another 22 M\$. It was built with the support of external consultancy, generating high expectations. HMIS was structured on three layers: central level $(\mathrm{MoH})$, territorial level (district public health authorities), and local level (all healthcare units of a district: hospitals, policlinics, dispensaries, rural health centres, ambulance services, and blood collection centres). The first phase comprised both central and territorial levels as well as one of the 42 districts of Romania, as a pilot district. The project provided expenses not only for hardware and software but also for training and management. The analysis of the system started in 1995 with the technical specifications, but, due to several bureaucratic obstacles and frequent changes at the highest level of the Ministry of Health, the contract was signed only in 1998 with the project integrator, Sema Group France - winner of the auction. The initial completion deadline was postponed from mid-1999 to the end of 2000, when it had to be ready for exploitation and planned to be flagged as a political success by the leaders of that time. Finally, by the end of 2000, a number of some 230 servers and more than 900 PCs were installed in 320 different places, including an intranet network with X25 connections, firewalls, the $\mathrm{R} / 3$ package of SAP for resource management, an adapted version of Grenoble University Hospital information system for electronic medical records (France), Hematos software for blood transfusion, Comshare for decision support, TeamLinks for document management, and an Oracle database management system². More than 400 persons attended the set of over 25 training courses.

\footnotetext{
References about the old versions (period 1996-1998) of the software are no longer available; some companies have disappeared, others still exist but their websites do not contain information about their old products.
} 
Unfortunately, even though it was considered to be much better prepared than the previous projects, the results were far below expectations (an official report phrased it as "modest results") with just a few components actually functional. This project became a "case study" for a further analysis [18], revealing several objective and subjective factors which generated this "failure" - a hard and expensive lesson. We can cite here some major factors which had a dramatic impact: (1) the entire organizational framework of the Romanian healthcare system had changed during the implementation of the project - the National Health Insurance House (NHIH) had just been established in 1997, taking over some responsibilities from the $\mathrm{MoH}$. Although all healthcare institutions remained the same, the information circuits changed and the contractor's proposals to update some parts of the project struck the inflexibility of the regulations imposed by the creditor; (2) there was no strategy at the governmental level to ensure the continuity of major projects, accompanied by frequent changes at decision-making levels or of the legislation; (3) unbiased/fair professional consultancy was missing (for example, the recommendations to avoid some inappropriate or non-interoperable components); (4) the terms used in the contract were sometimes ambiguous or not fully equivalent to the translated terms, generating misunderstandings or conflict situations; and (5) it was impossible to keep the staff trained especially for this project in the system. We can also add the dramatic drop of the national currency exchange rate in that period which decreased the capacity to fulfil the tasks without exceeding the budget, the acceleration of technological advances (by the time of delivery, some of the initially ordered products were already obsolete) and, finally, the mismanagement of the project in various places or moments. The saddest part was that despite the evidences, intermediate notifications and recommendations were disregarded, and a final report prepared by an ad-hoc nominated commission qualified the project as acceptable, smoothing the way to start an expensive rollout without a new auction. In the new version, big hospitals remained on the list, but some of them declined the offer as they had already started to implement other solutions. The rollout has never been completed and most of the new equipment was transferred to other governmental institutions [4].

However, this period also had a positive dimension, not related to the weak results of governmental projects: the (private) free market started to show up; several companies started to offer various IT products for physicians and healthcare units. Despite they had a minor role in this period, they grew and their presence influenced the next decades.

\section{2d Maturity Period}

The general trend at the end of the 90's and at the beginning of the new century in Eastern Europe was to get aligned with European values and standards, which would facilitate external contacts. The enlargement of EU became a priority for most European leaders. Romania became a "candidate country" in 2004 and a "EU member state" in 2007. Our external contacts extended and more and more young scientists benefited from scholarships or were involved in European projects.

\section{a) Education and Training}

Several programs to favour the inclusion of Eastern countries in European projects were initiated or got extended versions (Tempus, Erasmus) $[19,20]$. An intense bidirectional exchange of professionals took place. Romania received consistent and sustained support mainly as bursaries to facilitate the participation of young Romanian scientists in international conferences. Support came from several persons among whom we should mention at least Bernard Richards (more than 25 full bursaries for attending the 1996-1998 Harrogate conferences of the Health Group of the British Computer Society), Rolf Engelbrecht (22 bursaries for Medical Informatics Europe (MIE) 2000 conference in Hannover), and Jana Zvarova (over 10 participants at EuroMISE courses in Prague). All these exchanges had a visible impact - the main characteristic of the period was a marked increase of the qualitative level of both education and research. Unfortunately, two other negative parallel processes also showed up: the "brain-drain" boomed, several young well-trained specialists left the country and there was a drain within the country as specialists trained for our academic research projects found better paid jobs in other sectors. Our legislation has not given any help in this regard.

The contents of educational programs also improved during this period. The new context imposed new targets: adapt contents to get closer to practical applications, get involved in bio-medical research, and provide healthcare informatics professionals. Several collaborations with similar departments from abroad or with research groups started with very good results [21]. The National Council for Scientific Research launched attractive research programs, which lasted just a couple of years ago, since, unfortunately, the funding was drastically reduced during the economic crisis.

The efforts to initiate an educational program for health informatics professionals encountered several obstacles: the lack of a coherent strategy of the Ministry of Health, a long lasting ambiguity between the responsibilities of the Ministry of Health and the newly created National Health Insurance House, an inefficient communication between the Ministry of Education and the Ministry of Health, the inertia of the Ministry of Labour to update the list of professions to include "healthcare informatician" as an official potential job...etc. However, an important step was made in 2009, when a master program for "Healthcare Information Systems", coordinated by Prof. Lăcrămioara Stoicu-Tivadar, was introduced at the University Politehnica Timisoara, Faculty of Automation and Computers. The program had a modern curriculum [22], and lectures were updated yearly. The program was very well received by the students, with a rising demand during 2016 and 2017. The program prepares well-trained professionals to support the digital healthcare domain. Unfortunately, the impact on the specific labour market is still modest since the healthcare system is in a chronic financial crisis and hospitals have not shown yet any interest in recruiting new professionals, postponing sine die the refreshment of their professional health informatics staff.

One of the trends encouraged by the RSMI is to foster the introduction of digital technologies by interdisciplinary teams (MDs and ITs)to develop new and attractive methods in medical education [23]. 


\section{b) Implementation in Healthcare}

The failure of the "Healthcare Medical Information System" - HMIS project was perceived as an unfulfillment of the $\mathrm{MoH}$, while the newly created National Healthcare Insurance House (NHIH) took over the objectives and the funding of the previous plan. The reaction of the $\mathrm{MoH}$ was weak, they seemed rather happy to get rid of such a task. The redesigned project, renamed SIUI (Unique Integrated Information System, $\sim 20 \mathrm{M} €$ ) and coordinated by the NHIH started with a big delay (in 2002 instead of 1999), having its first components implemented in 2008 [24], with a systematic extension every year (some components being still under construction). The SIUI system preserved the main requirements of the previous project -i.e. to cover all levels and to comprise all citizens. All units of health services (hospitals, dispensaries, pharmacies, physicians, therapists...etc.) and all insured citizens received a unique identification code and an associated card; all services were recorded. The simple introduction of these procedures brought a noticeable improvement of the quality of data bases, reported activities, and resource management, by eliminating the duplicates of persons or services, allowing for a fast reporting process and a better monitoring and control of resources [4].

The SIUI system is quite complex [25]. Besides the main module, dedicated to contracting, reporting, billing and settlement, four other big modules perform specific tasks:

- ERP - electronic resource planning;

- SIPE - information system for electronic prescription, implemented since 2012;

- CEAS - electronic cards for healthcare insurance (the present card is just a key to allow the physician to access a patient's record);

- DES - electronic health record, in use since 2015, including a summary of vital data (minimum data set for emergency situations), the full medical history, the data of the current consultation and a list of attached documents.

The SIUI portal [25] contains several other details and documents for reporting, including the nomenclatures and guidelines for various situations.

The development and the implementation of the SIUI system certainly represented a major step towards the computerization of current medical practices. The success of SIUI implementation is acknowledged: healthcare leaders consider that it provides mostly positive outcomes but other users complain and accuse it of having numerous shortcomings. In almost ten years of operation, the system has had numerous "failures" that sometimes literally blocked the current medical activity.

Several weak features can be reported. First, the system is incomplete and only covers people who have the classical mandatory social health insurance. Although NHIH is the largest health insurance house in Romania, it is not the only system, and there are also other health insurance houses (e.g. the Health Insurance House of the Army) and a private system. Moreover, all medical activities, treatments, or drugs are not reimbursed or covered by the health insurance policy, and the corresponding information may be omitted in the patient record. Interfaces are not very friendly and the system is often qualified as difficult to use. The project did not impose standards to assure interoperability with similar European systems, which will probably raise new problems soon. There are also intense discussions about exaggerated prices paid for some components.

In addition, given that the use of SIUI was (almost brutally) imposed by NHIH, healthcare professionals, starting with general practitioners, were compelled to either learn how to use SIUI-based programs or to use other friendlier programs, which should have the same operational functioning. Indeed, the private sector was quick to react and several companies filled the market with various alternative applications, covering not only the production of mandatory reports in the format required by $\mathrm{NHIH}$, but also adding new features to the patient record or facilitating the management of care units. If general practitioners represented the first target, soon new applications were developed to address all medical specialties needs - dental offices, pharmacies, polyclinics ...etc. Some private companies have already conquered significant shares of the Romanian market (e.g. Syonic, Softeh, Sterio).

Hospitals have been in the forefront of software developers' attention just prior to the launch of IT projects by the Ministry of Health. Initial products were mainly ori- ented towards financial and administrative applications but there were also concerns for patient management and diagnosis, with a trend to extend the medical record. Among the most used applications, we can mention the Hospital Manager developed by InfoWorld, or Hipocrate developed by Romanian Soft Company.

Additional independent projects were implemented during the maturity period, with an impact on the medical world, mainly under the frame called PNCDI (National Plan for Research, Development, and Innovation [26]) coordinated by a national agency - CNCS (National Council for Scientific Research) and the Ministry of Information Technology or the Ministry of Health. We can mention here two significant examples. One example is the MediNet network coordinated by Marius Marginean and having Prof. Vasile Stoicu-Tivadar as IT manager [27]. It was a national general practitioners network (with 100 GPs at the start and 60 at the end), targeting $2 \%$ of Romanian population. Participating GPs had smart software called MedINS and they were reporting information to the network in a very easy and smart manner. The project participants were trained during 3 meetings. Very well received by the medical staff [28], the project was a success. Another important project and the first of this kind in Romania was developed in 2007, managed by Sorin Puscoci form the National Communications Studies and Research Institute (INSCC Bucharest), related to AAL (Ambient Assisted Living): the aim was to implement an eldercare solution with hardware and software support [29].

\section{Romanian Society of Medical Informatics}

\section{3a Foundation, Objectives, Organization, and Structure}

The community of people interested in the field of medical informatics took contour since the first National Symposium of Medical Informatics in 1977. It comprised people with various backgrounds, especially engineers, physicians, and mathematicians. The real existence of this community was confirmed by the series of annual confer- 
ences held since then. However, it was not formally registered as a professional association and had no organizational structure until the revolution of 1989.

The official foundation of the Romanian Society of Medical Informatics in 1990 [30] came as a natural confirmation of the existence of this community. As stated in its Statute:

"The Romanian Society for Medical Informatics, RSMI, is a legal entity registered as a scientific, professional, non-governmental organization aimed to promote the activities in the development of medical informatics in Romania and to represent the activities in the country and abroad. The activities of RSMI concern the stimulation and co-ordination of the activities of its members in promoting medical informatics in the country and the support of international co-operation in this field, which implies: organizing scientific and professional conferences, symposia, courses, exhibitions, and a collaboration with related organizations for such activities; publishing scientific, professional, and educational documents and papers in the field of medical informatics; disseminating information about conferences, publications, and links to websites on medical and health informatics; promoting scientific and professional contacts with similar societies at the international level; actively supporting scientists to attend international meetings; collaborating with Romanian Academy and the Academy of Medical Sciences in medical informatics research; collaborating with medical and technical universities in developing education and training in medical informatics."

RSMI has now around 120 members, a member count which remained almost stationary for the last decade.

The first president, elected in 1990, was Dr Virgil Moga from Sibiu, a cardiologist, and organizer of the national symposium in 1990 , followed in 1994 by Dr Virgil Enatescu from Satu-Mare, a psychiatrist, and the father of the RoMedInf conferences. The position of president was given to Prof. George Mihalas in 1998, seconded by Dan Farcas, Ioana Moisil, and Andrei Achimas-Cadariu (replaced in 2002 by Mihai Tarata) as vice-presidents, Tiberiu Spircu as scientific chair and Mariana Bazavan as secretary. Since 2010, the presidency is held by Prof. Lăcrămioara Stoi-
cu-Tivadar seconded by Gabriela Georgescu, Elena Podoleanu, and Marius Marusteri, as vice-presidents, and Mihaela Vida-Crisan as secretary. While RSMI members were at the beginning mainly academics and researchers, companies came by in the last few years. They supported the conferences and filled-in practical and economical issues. A new trend is now visible: young multidisciplinary teams are forming, combining people from different professional areas (physicians, engineers, nurses, informaticians, or mathematicians).

RSMI has six working groups covering various major areas of interest: education, EHR and interoperability, medical imaging, portable devices, dentistry informatics, and nursing informatics.

The legislative frame for professional associations in Romania is mostly designed for large associations. However, RSMI is a rather small society (there is no paid staff, and all activities are performed on a voluntary basis), which results in difficulties in various instances and when participating as a legal partner in national or international projects, and promoting initiatives or participation to official meetings or delegations. Considering the average living standard level, membership fees are low, almost symbolic.

\section{3b National Activities, Relations with Governmental Institutions and Professional Associations}

However, despite all these hurdles, several activities have been successfully carried out, mainly focused on the organization of national conferences and the participation in EFMI (European Federation for Medical Informatics) or IMIA (International Medical Informatics Association) events. When organizing national conferences, contacts were made with different governmental institutions, central authorities, universities and research institutions, other professional associations, and several companies. The echo to our invitations was in general very good, especially from universities and some software companies that could even sponsor our events, while the Academy of Medical Sciences became the co-organizer of several editions of our series of conferences. However, the support from the Ministry of Health was sporadic and much lower than our expectations while the National Health Insurance House completely ignored our events.

The consequent activity of the RSMI board along the years ensured the continuity of the series of national conferences. The audience was in general very good as well as the scientific level. Registration fees were kept as low as possible. Proceedings volumes were published for most editions. RSMI also introduced prizes for best papers. A full list of these meetings as well as other details about RSMI are available in[30].

RSMI has good contacts with other professional associations: ProRec Romania (a member of EuroRec), the Society of Dental Informatics, the Romanian Society of Medical Bioengineering, the Romanian Society for Applied Medical Informatics, the National Society of Pure and Applied Biophysics, the Association of Family Physicians, the Romanian Association for Telemedicine and Space Applications for Health, and HL7 Romania. RSMI had, with each of them, at least one common event or cooperation within a project.

Another aspect of RSMI activity concerned the exploitation of the potential expertise of our members. Such expertise had been exploited even before the official foundation of RSMI. In 1986, the Centre of Health Statistics and Information (CCSS) of the $\mathrm{MoH}$ organized a series of training courses with RSMI members serving as lecturers. In the spring of 1989, the Romanian Academy created a Commission of Medical informatics, chaired by Dr. Dan Farcas. Later that same year, the Academy of Medical Sciences established a Commission of Informatics, chaired by acad. Stefan Milcu. The creation of these commissions had a strong impact on the way medical informatics was perceived: this recognition at an academic level was a key to open new doors and make further steps, like the introduction of medical informatics as a mandatory discipline in medical curricula or starting programs at the $\mathrm{PhD}$ level.

The leaders of the Ministry of Health tried to initiate similar actions, oscillating though between selecting a group of experts from CCSS and creating a commission with experts from the whole country. Both solutions were alternatively adopted, with 
long periods of inactivity, thus depriving this structure of any continuity.

In recognition of the professionalism of our members, RSMI was often invited to send experts to present lectures on various topics by companies involved in the promotion and the organization (often in tandem with other institutions or companies) of events on medical or healthcare "hot topics" of the moment.

\section{3c International Activities}

Even before the official founding of RSMI, Romania was represented at the level of "contact person" in IMIA since 1986 (approved in Prague by Prof. Shigekotu Kaihara, on the recommendation of Prof. Jan $\mathrm{H}$ van Bemmel). RSMI became an official IMIA member in 1994 (voted at the General Assembly in Dresden). Later that same year, RSMI joined EFMI, at the Council meeting held along MIE'94 in Lisbon. Romania has been represented at all EFMI and IMIA meetings and conferences since then, becoming one of the most active members despite this has been difficult, mainly due to financial reasons,

The political context in the early 90 's in Eastern Europe, including Romania, was favourable to international contacts. Initiatives came from both sides. Thus, during that period, we were happy to have close contacts with several healthcare informaticians who attended our conferences with the first wave being represented by a delegation from the UK, i.e. Graham Wright, Helen Betts, Jean Roberts, Bernard Richards et al., with whom we started systematic contacts, which resulted in the cooperation within a couple of European projects, most of them within the Tempus frame $[19,20]$. The extension of external collaborative contacts in European projects also had a positive impact on our research activities. Several scientific events have been organized in the last two decades by RSMI, sometimes together with other societies with adjacent activities, as mentioned above.

A specific historical feature of the last decade of the $20^{\text {th }}$ century was the transition of several countries of Eastern Europe from totalitarian to democratic political regimes, and from a centralized economy to an open market economy. The concern at the European level about monitoring such a unique historical process was practically translated by designing specific programs to stimulate international and inter-regional cooperation so as to facilitate a smooth transition. An initiative down this line came in 1996 from Marcelo Sosa Iudicissa, who worked at that time for the European Commission, proposing the creation of a dedicated EFMI WG - Medical Informatics in Countries in Transition (MICIT). A similar WG (Health Information for Development - HID) was also established in IMIA by Nora Olivieri from Argentina. These working groups organized several workshops over time, with overcrowded audiences and lively debates, presenting all kinds of challenges and obstacles encountered in various places. Romania held the chairship of HID (2001-2004) and MICIT since 1998. In 2007, after the inclusion of most East European countries to the EU, the term "country in transition" was no longer used and the EFMI WG was renamed as "Health Informatics for Inter-Regional Cooperation" -- HIIC. We are proud to mention that the presence of Romanian participation was often noticed, not only in the workshops organized by these WGs, but in general in various European and international conferences on medical informatics.

The success of national conferences and the numerous contacts with foreign specialists allowed us to dare to also organize international events. Thus, in 2001 RSMI organized the first EFMI Special Topic Conference (STC) in Bucharest entitled "Healthcare Telematic Support in Transition Countries" [31], which was a real success, being one of the few conferences in our country which received a good support from the Ministry of Health. Another STC was held in 2006 in Timisoara on the topic "Integrating Biomedical Information: from e-Cell to e-Patient" [32]. It had a large audience, being actually a joint event running in tandem with a EuroRec meeting, with a session of the "Semantic Interoperability" European project as well as with our national RoMedInf.

At the end of this section, we can mention that two members of our society also occupied leading positions in EFMI and IMIA. George Mihalas was EFMI president in 2006-2008, IMIA vice-president for Eu- rope in 2008-2010, EFMI honorary fellow in 2012, IMIA WG History vice-chair since 2014, and founding member of IAHSI - the International Academy of Health Sciences Informatics. Lacramioara Stoicu-Tivadar is chair of EFMI WG HIIC, was EFMI secretary in 2012-2014 and is EFMI vice-president since 2014.

\section{Current State of Medical Informatics in Romania and Recent Activities}

\section{4a Education and Training}

Medical Informatics is a mandatory discipline in all medical undergraduate studies. There is a master level for health information professionals at polytechnic universities in Timisoara and Bucharest as well as $\mathrm{PhD}$ programs in medical informatics. IMIA recommendations are followed. Educational programs must fulfil the standards imposed by the ARACIS agency (Romanian Agency for Quality Assurance in Higher Education [33]), which is responsible for the accreditation of all the educational institutions in Romania.

\section{4b Healthcare Implementations}

The National Health Insurance House (NHIH) has introduced SIUI, a complex information system that covers almost all healthcare units in Romania, with a good reporting system to the central level. It includes components dedicated to electronic prescriptions, healthcare insurance cards, and patient electronic health records. If SIUI had brought an actual improvement to resource management, it would still have to solve several issues, e.g. a poor design and an infrastructure that hardly covers the needs. Indeed, user acceptance has been very low, and the project paid no attention to making the system interoperable with IT components previously existing in the Romanian health information system or with similar programs in other European countries.

On the other hand, the private sector did perform well. Most users choose to use addi- 
tional or alternative programs, with interfaces friendlier than SIUI. Several hospitals had their information system before SIUI was launched, and they just made the adaptation needed for the reporting components in order to satisfy the NHIH imposed format. A positive point should be noticed here: NHIH encouraged the contributions from the private sector that could help users get digitalized, e.g. the SIUI portal [25] offers all technical specifications needed by developers to build compatible applications, including nomenclatures and coding systems.

The Ministry of Health has its own information system, with a virtual network comprising all public health authorities at the district level.

\section{4c Legislation, Standards, and Government Involvement}

Romania's accession to the EU in 2007 had positive consequences on the legislative domain and helps comply with European standards. However, since EU only makes recommendations in the domain of healthcare, the Romanian health law is not fully aligned with the one of other European countries. The sensitive issue of data protection is regulated by law 677 of 2001 [34], which was amended several times. The National Authority for the Surveillance of Personal Data Processing [34] has already prepared the guides and the Romanian translation of the last version of the General Data Protection Regulation (GDPR) 2016/679 [35], which should be applied as of May $25^{\text {th }} 2018$.

As far as the standards in medical informatics are concerned, besides the National Agency for standards, in 2006 HL7-Romania was founded, contributing to the further adoption of standards in Medical Informatics.

The involvement of governmental institutions in healthcare informatics activities (other than the ones included in the implementation of SIUI) was, in general, very low. NHIH showed no intention to have any contact with RSMI specialists and ignored all the invitations to attend our conferences. They rather relied on external expertise, which seemed to be sometimes quite inappropriate, yielding poor results and low user acceptance.
In 2014, the Academy of Medical Sciences established a Commission on Medical Informatics and Data Protection, whose purpose was to become an "Observatory", able to offer good quality surveys over various features of this domain in Romania.

\section{4d Medical Informatics Research and Scientific Activities}

Research activities are mainly carried out in universities and may be of three types: participation to European, inter-regional, or national projects, collaborative actions between various departments (clinical, engineering, fundamental medical research, public health...etc.), and activities within doctoral or master programs in the preparation of theses or dissertations. The scientific level is in general good or very good, sometimes yielding excellent results. Most private companies involved in biomedical/health informatics have their own R\&D departments. There is no national strategy in this direction and central institutions are less involved in these activities.

The participation in both national and international conferences is good. At the national level, there is one journal on this domain: Applied Medical Informatics (AMI) [36], led now by Prof. Sorana Bolboaca, and published quarterly since 1995 by Iuliu Hatieganu University of Medicine and Pharmacy in Cluj-Napoca. The journal, officially registered by the National Council of Scientific Research, is indexed in international databases (Copernicus, EMBASE...etc.).

An important scientific event is represented by the periodic RoMedInf conferences organized by RSMI. RoMedInf 2017 was held in Timisoara, on 23-24 November 2017. It was a jubilee event, marking the " $40^{\text {th }}$ birthday" of the conference since the first national symposium of medical informatics. The program comprised five plenary sessions, with a foreign keynote speaker, Prof. Jaime Delgado. The 36 oral presentations and 10 posters were distributed among eight parallel sessions. The audience was very active, especially in the session on Nursing Informatics and in the panel on Education. The papers will be published in the AMI journal [36]. Details about the program and the four prizes can be found on RSMI website [30].

\section{4e Future Perspectives}

The present optimistic forecast for the Romanian economy is expected to have a positive impact on the development of an e-health sector that could promote the implementation of several pending plans. This will have an impact also on medical informatics education and training at all levels. The newly created Commission of Medical Informatics and Data Protection of the Romanian Academy of Medical Sciences has been involved in bridging central institutions and creating a common platform. This should help the development of a coherent and realistic e-health strategy that could answer the numerous still unsolved issues, taking into account the needs of human resources in the field.

For RSMI, the major objectives for the near future are to bring more and more young people to healthcare informatics to work on the major international topics such as systems medicine and artificial intelligence, to promote interdisciplinarity, to contribute to the development of knowledge in these areas, to cooperate with companies having research works in these domains, and to be a voice in relation with local and national authorities.

\section{Discussions and Conclusions - Lessons Learned}

Romanian medical informatics history is rich in years and content. Its development followed the natural way in parallel with computer technology applications in all domains, including medicine and healthcare. As expected, the footprint of the socio-political context yielded specific evolution, marking the events with distinctive features. Each period has had its good and bad parts. Political seclusion of the pioneering period has partially limited the practical results, despite the great enthusiasm of the pioneers. The first lesson learned is: "Science is a shared thesaurus and documentation is essential for achieving good and practical results". The temporary political relaxation of the 70's brought in an impulse in all areas, raising the trust in our capacity to join the main stream of scientific progress. In a period of very fast technological developments, the role of periodic meetings, 
especially the international conferences, became obvious. Other lessons learned are: "An (international) meeting equals six months in a library" and "Have faith, go and share your results, too".

The big political change of the 90 's broke down all formal barriers. However, the economic divide endured, limiting the access to the newest technologies. Moreover, as the drop in various previous constraints was not replaced by an organized frame, the efforts were dissipated towards various directions, represented by small unrelated projects, offering in the early 90 's an image of rather chaotic developments. The involvement of governmental institutions was welcome from this point of view, several initiatives merged into larger projects prepared with external consultancy and a legislative frame has emerged. But the frequent high-level changes had a strong negative impact on the success of these projects. More lessons learned are: "A coherent development of a domain needs a sound legislative base, a reliable organizational frame, a strong and continuous political support as well as a deep involvement of competent professionals".

The progress of Romanian medical informatics during the last decade was visible in academic activities (education and research) as well as in industry and IT implementations in healthcare. However, the dialogue between all stakeholders is still feeble, limiting the rise to the true potential. "Progress is the result of a collective work".

This historical survey helps us to better understand the important role of RSMI, as a professional organization, in assuming its role to coagulate all these forces, bringing its contribution to both the national and the international development of medical informatics.

\section{Acknowledgement}

The authors wish to thank Dr. Dan D Farcas, former director of the Centre of Health Statistics and Information (CCSS) of the Ministry of Health, for the rich bibliography made available to the authors.

\section{References}

1. Mihalas GI, Zvarova J, Kulikowski C, Ball M, van Bemmel JH, Hasman A, et al. History of Medical Informatics in Europe - A Short Review by Different Approach. Acta Informatica Medica 2014;22(1):6-10.

2. Mihalas GI. Evolution of Trends in European Medical Informatics. In: Masic I, Mihalas G (editors). Contributions to the History of Medical Informatics. Sarajevo: Avicena; 2014. p. 85-102.

3. Farcas D. Experiences of Modeling the Activity of Neuronal Networks by Means of Electronic Digital Computers. Elektronische Informationsverarbeitung und Kybernetik (E.I.K.). Berlin: Akademie Verlag 1966;2(4):213-21.

4. Farcas D. Informatica de sanatate [in Romanian]. Bucuresti: Ed. Univ. Carol Davila; 2014.

5. Mihalas GI: Romanian medical informatics and professor Jan H. van Bemmel's support - Dr. Honoris Causa bestowed by Victor Babes University. Methods Inf Med 2006;45(6):668-70.

6. Popescu O, Enatescu V, Farcas D, Mihalas GI, Petrescu O, Popa S. Informatica Medicală [in Romanian]. Bucuresti: Editura Medicală; 1988.

7. Mihalas GI. Health Informatics Education for Pharmacy Students in Romania. Proc MIE'97. Stud Health Technol Inform 1997;43:702-6.

8. Hasman A, Albert A, Wainwright P, Klar R, Sosa $M$ (editors). Education and training in health informatics in Europe. Stud Health Technol Inform 1995;25.

9. Recommendations of the International Medical Informatics Association (IMIA) on education in health and medical informatics. Methods Inf Med 2000;39:267-77.

10. Mihalas GI, Lungeanu D. Computer simulation programs for teaching biostatistics to medical students. In: Richards B, De Glanville H (editors). "Current Perspectives in Healthcare Computing" Proc HC 96 Conference, Harrogate; 1996:353-8.

11. Mihalas GI. Doctoral Level in Medical Informatics in Romania. In: Brender J, Christensen JP, Scherrer JR, McNair P (editors). Proc MIE 96, Stud Health Technol Inform 1996;34:910-4.

12. Mihalas GI, Lungeanu D. Strategy for Medical Informatics Education at the University of Medicine and Pharmacy in Timisoara. Yearb Med Inform 1997:113-9.

13. Mihalas GI. Milestones in Romanian Medical Informatics. Med Arh 2004;58(1 Suppl 2):84-5.

14. Mihalas GI, Lungeanu D, Kigyosi A, Vernic C. Classification Criteria for Simulation Programs Used in Medical Education. Medinfo 1995;8 Pt 2:1209-13.

15. Mihalas GI, Lungeanu D, Vernic C, Kigyosi A, Petrescu M. Medical Informatics for "Allied" Profiles. Stud Health Technol Inform 2000;77:546-8.

16. Rîpanu A, Oprisan M. Evaluation of the Computer-Based Dispatching System for Emergency Medical Dispatch. Stud Health Technol Inform 2000;77:244-50.

17. Farcas D. The Health Management Information System of Romania. Proc MIE'99. Stud Health Technol Inform 1999;68:140-5.

18. Mihalas GI. Analysis of Barriers in Implementation of Health Information Systems - EFMI conference introductory address. Stud Health Technol Inform 2008;134:21-6

19. Filip F, Mihalas GI, Dimitriu R, Jipescu I, Lungeanu D, Popescu A, et al. Communication Networks for Healthcare: RENEHEMA Tempus Project Experience. In: Richards B (editor). Tri-partite bridges: Educators, Providers and Users. Tempus CME-0255-96 Seminar Proc. Sinaia; 1998: 19-27.

20. Lungeanu D, Mihalas GI, Bazavan M, Dimitriu R, Sima R. Communication Between higher education and industry. In Richards B (Ed): Tri-partite bridges: Educators, Providers and Users. Tempus CME-0255-96 Seminar Proc. Sinaia; 1998:28-36.

21. Lungeanu D, Dimitriu R, Bazavan M, Sima R, Richards B, Neame R, et al. Medical Informatics Educational Tasks Seen from Practical Prospective. Proc. MIE'99. Stud Health Technol Inform 1999;68:497-9.

22. http://siis.aut.upt.ro/ (last accessed on Jan $20^{\text {th }}$ 2018) [in Romanian].

23. Nicola S, Stoicu-Tivadar L, Virag I, Crisan-Vida M. Leap motion supporting medical education. $12^{\text {th }}$ IEEE Intl. Symposium on Electronics and Telecommunications (ISETC'16), Timisoara, Romania; 2016: 153-6.

24. http://www.cnas.ro/ (last accessed on Jan $20^{\text {th }} 2018$ ) [in Romanian].

25. http://siui.casan.ro/cnas/node (last accessed on Jan $20^{\text {th }} 2018$ ) [in Romanian].

26. http://uefiscdi.gov.ro (last accessed on Jan $20^{\text {th }}$ 2018).

27. http://cnsmf.ro/proiecte/proiecte-finalizate/ proiectul- gp-medinet/, Medinet GP project (last accessed on Jan 20 2018) [in Romanian].

28. Stoicu-Tivadar L. Sisteme informatice aplicate în servicii de sănătate [in Romanian]. Timişoara: Ed. Politehnica; 2005.

29. Stoicu-Tivadar V, Stoicu-Tivadar L, Puşcoci S, Berian D, Topac V. Web Service-based Solution for an Intelligent TeleCare System. In: Fodor J, Klempous R, Paz Suárez Araujo C (editors). Recent advances in intelligent engineering systems. Springer; 2012.

30. www.srimed.ro (last accessed on Jan $20^{\text {th }} 2018$ ) [in Romanian]

31. Mihalas GI, Engelbrecht R, Bazavan M, Hofdijk J, Naszlady A (editors). Healthcare Telematic Support in Transition Countries. Timisoara: Eurobit; 2002.

32. Reichert A, Mihalas GI, Stoicu-Tivadar L, Schulz $\mathrm{S}$, Engelbrecht R (editors). Integrating Biomedical Information: From eCell to ePatient. Amsterdam: IOS Press; 2006.

33. http://www.aracis.ro/nc/en/aracis/ (last accessed on Jan $20^{\text {th }} 2018$ )

34. http://www.dataprotection.ro/ (last accessed on Jan $20^{\text {th }} 2018$ )

35. https://gdpr-info.eu/ (last accessed on Jan $20^{\text {th }}$ 2018)

36. http://ami.info.umfcluj.ro/index.php/AMI (last accessed on Jan 20 2018 )

Correspondence to:

Prof. Dr. George I Mihalas

Academia de Stiinte Medicale Filiala Timisoara

UMF Victor Babes

P-ta Eftimie Murgu nr. 2

300 041, Timisoara

Romania

E-mail:mihalas@gmail.com 